\title{
Characteristics of microscopic pore-throat structure of tight oil reservoirs in Sichuan Basin measured by rate-controlled mercury injection
}

https://doi.org/10.1515/phys-2018-0086

Received May 16, 2018; accepted Aug 17, 2018

\begin{abstract}
Based on the results of rate-controlled mercuryinjection experiments, the microscopic pore-throat structure characteristics of tight sandstone in Sha-1 Section and tight limestone in Da'anzhai Section of Sichuan Basin were quantitatively characterized. The results show that the pore radius distribution characteristics of tight oil reservoirs are similar. The main distribution is between $100 \sim 190 \mu \mathrm{m}$, and the average pore radius is $160 \mu \mathrm{m}$. While the distribution of the throat radius of tight sandstone and limestone is quite different, the distribution of the throat of sandstone samples is relatively concentrated, and the distribution of the throat of limestone samples is relatively sparse. There is a good positive correlation between the average throat radius and permeability, but the correlation between fractal dimension and permeability is not obvious. This indicates that the permeability is mainly affected by the radius of the throat. The pore-throat ratio in tight oil reservoirs is relatively large, and the resistance to seepage is greater during development. Therefore, during the development of tight oil, measures should be taken to increase the radius of the throat, reduce the ratio of pore radius to pore-throat radius, and improve the seepage capacity of the reservoir, thereby improving the development of tight oil.
\end{abstract}

Keywords: Rate-controlled mercury injection; tight oil; pore-throat characteristics; fractal; Sichuan Basin

PACS: 91.25.Za; 91.60.-x; 91.65.-n; 93.85.-q; 93.90.+y

\section{Introduction}

Tight oil is new area for unconventional oil and gas exploration and development after shale gas [1, 2]. It is praised as "black gold" by the oil industry [3]. Tight oil refers to the accumulation of petroleum in the system of dark shale, argillaceous silt and sandstone intercalation that are rich in organic matter and have very poor permeability, which occurs in the form of adsorption or free state [4]. The boundary of the physical properties of the tight layer is determined. The surface air permeability is $<1.0 \times 10^{-3} \mu \mathrm{m}^{2}$, the underground pressure permeability is $<$ or equal to $0.1 \times 10^{-3} \mu \mathrm{m}^{2}$, and the porosity is less than $10 \%$ [5]. The Jurassic unconventional oil in the Sichuan Basin is continuously distributed over a large area and has a large resource potential. The tight oil reservoirs in Sichuan Basin have poor pore-throat structure and strong heterogeneity. The tight reservoir pore-throat geometry (pore type, shape, size, and distribution) not only controls the physical properties of the reservoir, but also directly affects the production and recovery of tight oil. It has been a popular topic for scholars [6-8].

Xiao Qianhua [9] used cryogenic nitrogen adsorption technology to study the microscopic pore structure characteristics of reservoir rocks in typical tight oil regions. Li Bo [10] visualized the pore type of tight oil reservoirs in the Da'anzhai Section of the Middle Jurassic Ziliujing Formation using thin-slide observation and scanning electron microscopy techniques. CT scanning techniques were used to reconstruct the three-dimensional microscopic pore-throat model of reservoir-dense limestone. It was found that a large number of nano-sized pores ex-

\footnotetext{
Zhengming Yang, Shengchun Xiong: University of Chinese Academy of Sciences, Beijing 100049, P. R. China; Institute of Porous Flow and Fluid Mechanics, Chinese Academy of Sciences, Langfang, Hebei, 065007, P. R. China; Department of Porous Flow \& Fluid Mechanics, Research Institute of Petroleum Exploration \& Development, PetroChina Company Limited, Langfang, Hebei, 065007, P. R. China
} 
Table 1: Thecharacterization parameters of rate-controlled mercury injection

\begin{tabular}{|c|c|c|c|c|c|c|c|c|c|c|}
\hline Sample & Lithology & $\Phi / \%$ & K & $\mathrm{R}_{t} / \mu \mathrm{m}$ & $\mathrm{R}_{p} / \mu \mathrm{m}$ & $\eta$ & $\mathrm{S}_{f} / \%$ & $\mathrm{~S}_{p} / \%$ & $\mathrm{~S}_{t} / \%$ & $\mathrm{P}_{d} / \mathrm{MPa}$ \\
\hline H19 & Sandstone & 6.13 & 0.556 & 1.26 & 158.29 & 156.79 & 56.37 & 20.95 & 35.42 & 0.252 \\
\hline H21 & Sandstone & 5.65 & 0.283 & 0.91 & 156.12 & 194.94 & 50.35 & 16.62 & 33.73 & 0.523 \\
\hline 52 & Sandstone & 3.47 & 0.082 & 0.80 & 152.91 & 186.48 & 39.53 & 4.31 & 35.22 & 0.516 \\
\hline 58 & Sandstone & 3.96 & 0.415 & 1.33 & 136.69 & 114.63 & 45.08 & 5.89 & 39.20 & 0.171 \\
\hline 60 & Sandstone & 3.95 & 1.41 & 1.43 & 135.49 & 106.03 & 56.79 & 10.72 & 46.07 & 0.130 \\
\hline 89 & Limestone & 2.14 & 0.014 & 0.54 & 145.48 & 282.12 & 8.80 & 1.11 & 7.70 & 1.025 \\
\hline 103 & Limestone & 3.06 & 0.265 & 0.92 & 151.44 & 187.79 & 17.84 & 5.08 & 12.76 & 0.442 \\
\hline $108-2$ & Limestone & 2.14 & 0.287 & 0.79 & 144.72 & 216.12 & 27.98 & 8.06 & 19.92 & 0.483 \\
\hline $109 \mathrm{~A}$ & Limestone & 1.76 & 0.059 & 0.47 & 150.51 & 335.07 & 14.70 & 2.11 & 12.58 & 1.09 \\
\hline $114 \mathrm{~A}$ & Limestone & 2.25 & 0.632 & 1.21 & 144.47 & 145.23 & 37.23 & 14.11 & 23.12 & 0.294 \\
\hline $132-1$ & Limestone & 2.24 & 0.241 & 0.85 & 147.13 & 188.11 & 13.61 & 2.24 & 11.38 & 0.565 \\
\hline
\end{tabular}

$\Phi$-porosity; K-permeability, $10^{-3} \mu \mathrm{m}^{2} ; \mathrm{R}_{t}$-average throat radius; $\mathrm{R}_{p}$ - average pore radius; $\eta$-pore-throat radius ratio; $\mathrm{S}_{f}$-final total mercury saturation; $\mathrm{S}_{p}$-pore mercury saturation; $\mathrm{S}_{t}$-throat mercury saturation; $\mathrm{P}_{d}$-displacement pressure. (the porosity of the rock samples is the conventional gas measurement porosity using the nitrogen test, and the permeability is the Klinkenberg permeability measured when the net confining pressure is $2 \mathrm{MPa}[18,19])$.

ist within the reservoir matrix, and pore-throat connectivity was poor. Zhou Shangwen [11] applied the NMR technique to carry out movable fluid tests on the samples of the Jurassic tight oil reservoir in the Sichuan Basin. The results of the study showed that the fluid content of the tight oil reservoir is very low and mainly distributed in small pores; its fluid availability is poor and difficult to develop. The above studies mainly focused on pore-throat type analysis based on the experimental results, but the pore and throat radius distributions were not quantitatively characterized. The influence of pore-throat structure on seepage capacity was also not discussed. Due to capillary pressure, the conventional mercury-intrusion technique will exhibit a low numerical value when the microscopic pores and throats of tight oil reservoirs are characterized. High-pressure mercury intrusion has an extremely high mercury-inlet pressure, which can cause artificial cracks. Large errors persist in the testing of small pores [12]. The rate-controlled mercury-injection technology ensures the quasi-static process of mercury ingression at a very low mercury ingression rate. According to the rise and fall of the mercury ingression, the microscopic pore structure parameter information can be obtained and the number of pores and throats can be directly obtained. Capillary pressure curves of the pores and throats are provided and the microscopic pore structure parameters, including the pore-throat radius distribution, are given. It also provides information that reflects the development of pores, throats, and the degree of development (the ratio of pore-radius to porethroat radius) between pores and throats [13]. Taking the tight reservoirs of the Sha-1 and Da'anzhai sections of the
Shaxiamiao Formation in the middle-lower Jurassic in the Sichuan Basin as an example, the authors used the RMI test technique to analyze the porosity, throat, and throat ratios of tight reservoirs. The microscopic pore structure of these reservoirs was finely characterized and the pore structure was studied using fractal theory. To provide a theoretical basis for the efficient development of tight reservoirs in the research region, the influence of the porethroat structure of tight reservoirs on the seepage capacity was explored.

\section{Sample}

The Jurassic in the Sichuan Basin is mainly a set of inland fluvial and lacustrine deposits. Oil and gas are mainly distributed in the Middle-Lower Jurassic. The middle section of the Shaximiao Formation in the Lower and Middle Jurassic, the Liangshang Section and the Da'anzhai Section of the Liangshan group are three main production zones. Over $90 \%$ of the crude oil in the Chuanzhong area is produced from these three sections [14-16]. The samples for this study were taken from the Sha-1 Section of the Shaximiao Formation and the Da'anzhai Section, and the constant velocity mercury intrusion data of the core (Table 1 ). The selected lithology of the sand sample from the first section was sandstone with a porosity of $3 \%$ to $6 \%$ and permeability between $0.082 \times 10^{-3} \mu \mathrm{m}^{2}$ to $1.41 \times 10^{-3} \mu \mathrm{m}^{2}$. The lithology of the reservoir in the Da'anzhai Section is in the form of shell limestone. Six of the samples were selected for study and the porosity is between $1.76 \%$ and $3.06 \%$, 
the matrix permeability is between $0.014 \times 10^{-3} \mu \mathrm{m}^{2}$ and $0.287 \times 10^{-3} \mu \mathrm{m}^{2}$, and the Da'anzhai Section is the source of hydrocarbons. The type of rock organic matter is mainly type II, and the value of $R_{o}$ is between $0.9 \%$ and $1.5 \%$. The abundance of petroleum resources with a source rock thickness $>20 \mathrm{~m}$ is $(6 \sim 10) \times 10^{4} \mathrm{t} / \mathrm{km}^{2}$ [17]. It can be seen from the above data that the main strata of the Shahemiao Formation and the Da'anzhai Section in the Sichuan Basin have extremely poor physical properties and are typical of tight oil reservoirs.

\section{Experimental method}

During the experiment, when the injected mercury enters the main throat (Figure 1a), the pressure gradually rises. The pressure drops rapidly after breakthrough (Figure $1 \mathrm{~b}$ ). The first pressure drop can be seen at $P_{1}$. Then mercury gradually fills up the first pore and enters the next secondary throat, resulting in a second pressure fluctuation
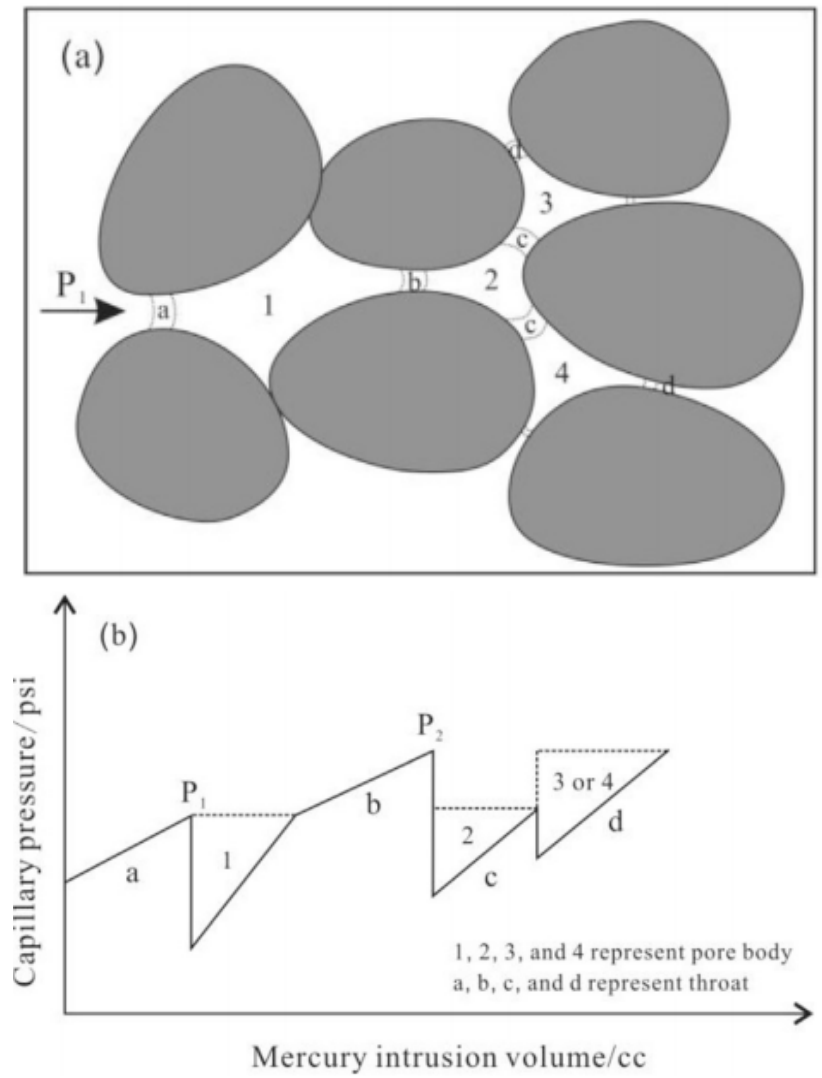

Figure 1: Rate-controlled mercury injection testing reservoir pore structure schematic. (a) Simplified schematic of pore body and throat configuration and (b) capillary pressure fluctuation and pore volume response at $\mathrm{P}_{2}$. Next, all the secondary pores controlled by the main throat are filled successively until the pressure rises to the pressure at the main throat, which is a complete pore unit. The radius of the throat is determined by the pressure value of the breakthrough point, and the size of the pores is determined by the volume of mercury ingress, thus separating the pores and the throat in the core [13]. The ratecontrolled mercury-injection instrument used in this experiment was an ASPE 730 rate-controlled mercury analyzer, manufactured by the United States Coretest Corporation. The mercury feed pressure was 0-1000psi (about $7 \mathrm{MPa}$ ), the mercury feed rate was $0.00005 \mathrm{~mL} / \mathrm{min}$, and the contact angle was $140^{\circ}$. The interface tension coefficient was $485 \mathrm{dyn} / \mathrm{cm}$. The experimental sample was obtained by drilling a plug rock sample with a diameter of $2.5 \mathrm{~cm}$, drying it after washing oil and taking a small rock sample from the plug rock sample. The average volume of the sandstone sample was $3.7 \mathrm{~cm}^{3}$ and the average volume of the limestone sample was $6.5 \mathrm{~cm}^{3}$, and then a ratecontrolled mercury injection experiment was performed after vacuuming.

\section{Results and discussion}

\subsection{Pore-throat distribution characteristics}

\subsubsection{Pore radius distribution characteristics}

By analyzing the results of RMI experiments, we can see that the pore radius distribution of tight sandstones in the 5 sands (Figure 2a) is similar to the distribution of the pore radius of the tight limestones in the 6 Da'anzhai Sections (Figure 2b). Distribution in $100 \mu \mathrm{m} 190 \mu \mathrm{m}$, the peak is about $160 \mu \mathrm{m}$. The predecessors found that their pore radius was distributed in the range of $100 \mu \mathrm{m} 200 \mu \mathrm{m}$ in the experiment of ultra-low permeability and tight permeability reservoirs. The peak value was about $140 \mu \mathrm{m}$ [2022]. Comparing the pore radius distribution characteristics of tight sandstones of Chang 6 and Chang 8 in the Ordos Basin, the main distribution is $100 \mu \mathrm{m} \sim 160 \mu \mathrm{m}$, and the peak is about $150 \mu \mathrm{m}$ [23]. Thus, for ultra-low permeability [24] and tight reservoirs, the effect of pore radius distribution on reservoir permeability is not significant.

\subsubsection{Throat radius distribution characteristics}

The experimental results show that the characteristics of the distribution of the tight sandstone throat of the Sha-1 

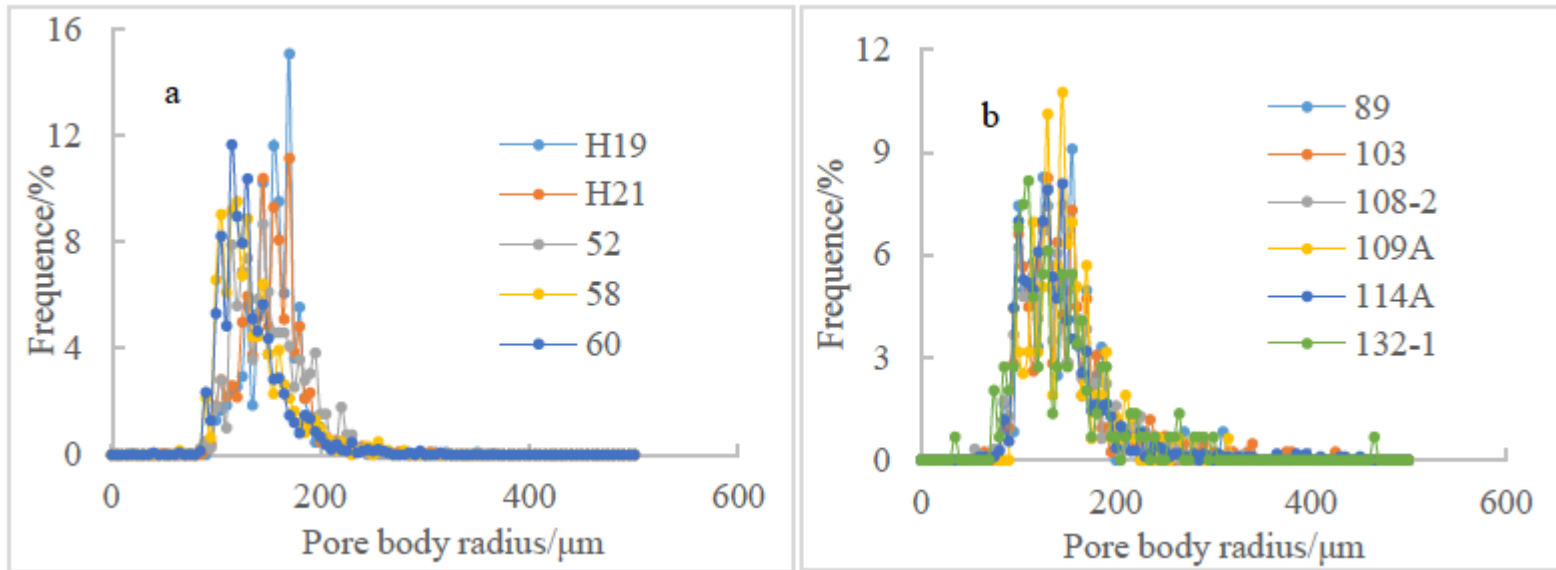

Figure 2: Pore size distribution by rate-controlled mercury injection of the samples
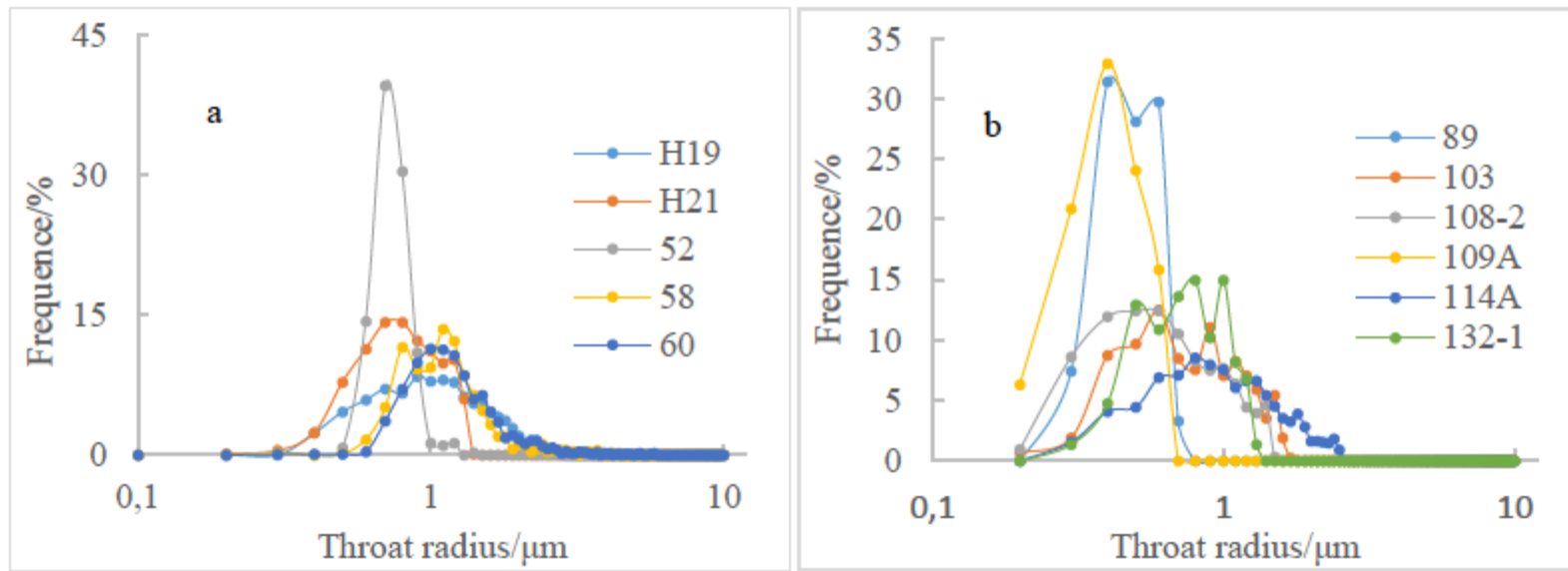

Figure 3: Throat size distribution by RMI of the samples

Section (Figure 3a) and the characteristics of the distribution of the limestone throat of the Da'anzhai Section (Figure $3 b$ ) are quite different. The distribution of throats in sandstone samples is relatively concentrated. The distribution of throats in limestone samples is relatively sparse. The radius of the throat of the sandstone is generally distributed between $0.2 \mu \mathrm{m}$ and $1.8 \mu \mathrm{m}$ with an average of approximately $0.5 \mu \mathrm{m}$. The main body radius of the limestone throat is $0.1 \mu \mathrm{m}$ to $2.1 \mu \mathrm{m}$, with an average of $0.7 \mu \mathrm{m}$. As can be seen in Figure 3(b), the greater the permeability, the wider the distribution range and the more the peak distribution shifts to the right. Figure 4 shows the cumulative frequency distribution of five sandstone cores with different permeabilities. The cores with poor permeability and the small throats occupy a small part. When the value of permeability is $0.632 \times 10^{-3} \mu \mathrm{m}^{2}$ and $0.014 \times 10^{-3} \mu \mathrm{m}^{2}$, the throat with a radius $<1 \mu \mathrm{m}$ occupies $40 \%$ and more than $90 \%$ respectively. There is a positive correlation between the average throat radius and permeability (Fig- ure 5). The correlation coefficient is greater than $0.9\left(R^{2}=\right.$ 0.918 ), indicating that the permeability of tight oil reservoirs is greatly affected by the throat, which is consistent with previous research results [25]. Waterflooding is an important technology for oilfield development [26]. However, with the decrease of permeability, the pore-throat of ultralow permeability reservoir is smaller and the fluid-solid coupling is stronger $[27,28]$. The higher the irreducible water saturation, the larger the starting pressure gradient. Therefore, the ability of porous media to allow fluid to flow through is becoming weaker [29]. At the same time, when the mainstream throat radius is $<1 \mu \mathrm{m}$, the actual permeability of waterflooding will be reduced exponentially; therefore, the likelihood of waterflooding will be increased [30]. Some studies also have suggested that a throat radius $>1.0 \mu \mathrm{m}$ has an important influence on core fluid flow. When the proportion of throats with a radius $>1 \mu \mathrm{m}$ is less than $40 \%$, it is considered that the development of reservoir water injection is not feasible [31]. The 


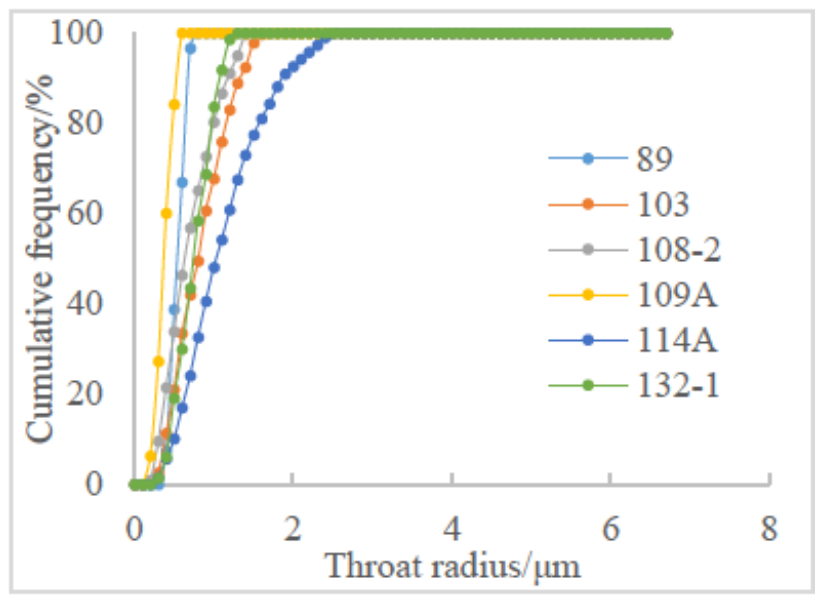

Figure 4: The cumulation frequency curves versus the throat radius of limestone

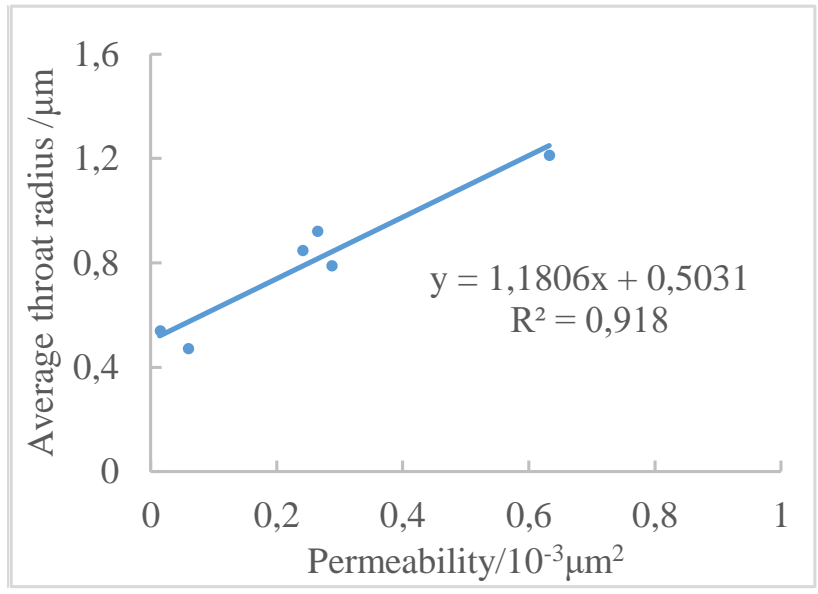

Figure 5: Correlationship between average throat radius and permeability

proportion of the total pore volume occupied by the throat with a radius $>1.0 \mu \mathrm{m}$ in tight reservoirs in the central Sichuan region is between $3 \%$ and $35 \%$. Therefore, it is difficult for the tight reservoirs in this area to be waterinjected and it is easy to cause various sensitive injuries, affecting single well productivity.

\subsection{Capillary curve features}

The pore and throat pressure and total capillary pressure curves, provided by the rate-controlled, mercury-injection test, can be used to visually reflect the relationship between mercury-inlet pressure, effective pore volume, effective throat volume, and total effective pore-throat volume [32, 33]. According to the tight rock sample, capillary pressure test results in the study area, there are 4 main types of pressure curves for rate-controlled mercuryintrusion capillary tubes, as shown in typical sandstone samples $\mathrm{H} 19$ and 52 (Figure 6a), and typical limestone samples 89 and 108-2 as shown in Figure $6 \mathrm{~b}$. The detailed pore structure parameters are shown in Table 1. For the sandstone sample H19, the expulsion pressure is $0.252 \mathrm{MPa}$, and the overall capillary drag-force curve in the early stage of mercury ingression is consistent with the pore capillary pressure curve. This indicates that mercury saturation is mainly controlled by pores in the early stage. As the pressure of incoming mercury increases, the pore capillary pressure curve becomes steep, and the overall mercury-influx curve is consistent with the capillary pressure curve of the throat. For sandstone sample 52, the expulsion pressure is $0.516 \mathrm{MPa}$, which is higher than the expulsion pressure of sample H19. In the early stage of mercury ingression, the total mercury saturation is mainly controlled by the throat. The capillary pressure curve of 89 in the limestone sample is similar to that of the sandstone sample H19, and the capillary pressure curves of 1082 and 52 are similar. However, the final mercury saturation of the limestone sample is lower than the final mercury saturation of the sandstone sample, which is related to its lithology. On the whole, for all rock samples in the study area, the pore mercury pressure curve gradually became steeper, parallel to the vertical axis, as the mercury-inlet pressure gradually increased (Figure 6).

\subsection{Pore structure fractal features}

Fractal geometry is a branch of mathematics [34]. It can describe complex things in detail. The pore structure of reservoir rocks has fractal features [35-40], which can be characterized quantitatively by fractal dimension. Based on the capillary beam model, the capillary pressure is calculated as follows:

$$
P_{c}=\frac{2 \sigma \cos \theta}{r}
$$

In the formula: $P_{c}$ is the capillary pressure, MPa; $\sigma$ is the interfacial tension, $\mathrm{N} / \mathrm{m}$; $\theta$ is the contact angle, $\left({ }^{\circ}\right) ; r$ is pore radius, $\mu \mathrm{m}$.

The relationship between capillary force and wetting saturation can be written as [37]:

$$
\log S=(D-3) \log P_{C}+(3-D) \log P_{\min }
$$

In the formula: $S$ is the cumulative pore volume fraction in the rock, whose pore radius is smaller than a certain value. In the mercury-injection test, saturation of the wetting phase corresponding to the capillary pressure, $P_{c}, \%$; 


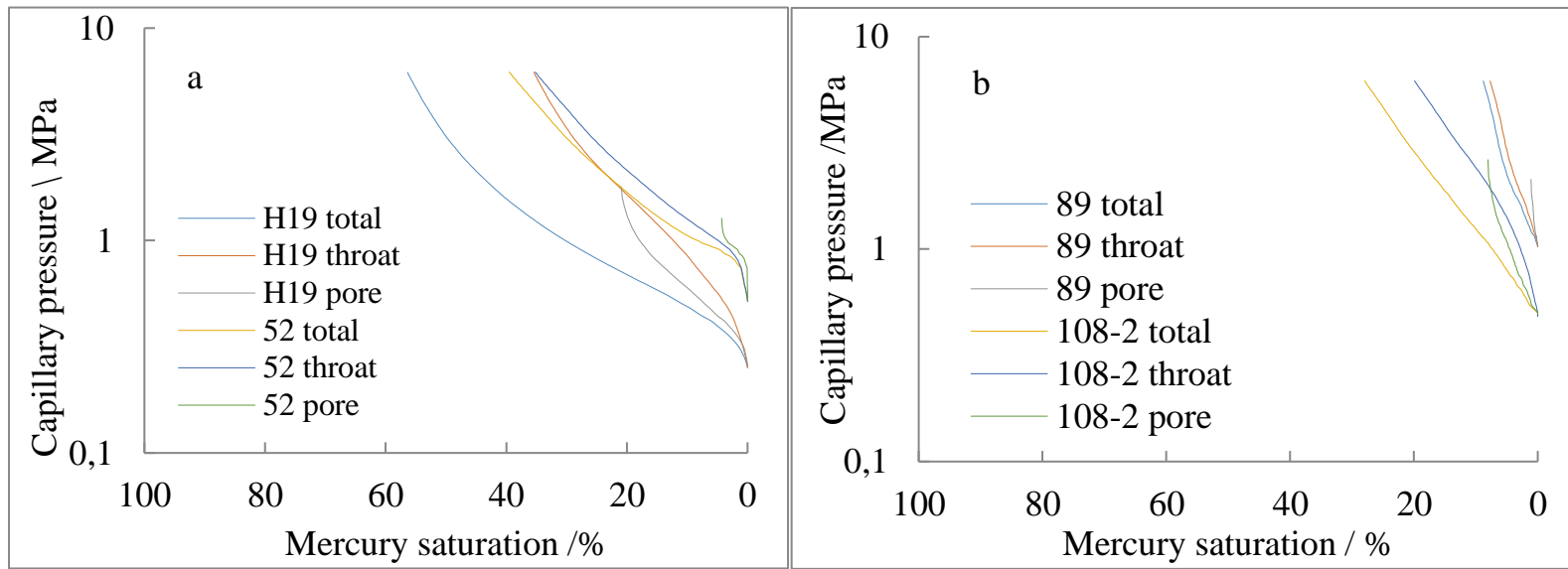

Figure 6: Capillary pressure curves of the representative samples

Table 2: Fractal dimension of sandstone and limestone

\begin{tabular}{cllcccc}
\hline Sample & Lithology & $\Phi / \%$ & $K$ & $\eta$ & $D$ & $R^{2}$ \\
\hline H19 & Sandstone & 6.13 & 0.556 & 156.79 & 2.7393 & 0.989 \\
H21 & Sandstone & 5.65 & 0.283 & 194.94 & 2.7066 & 0.994 \\
52 & Sandstone & 3.47 & 0.082 & 186.48 & 2.7812 & 0.997 \\
58 & Sandstone & 3.96 & 0.415 & 114.63 & 2.8035 & 0.986 \\
60 & Sandstone & 3.95 & 1.41 & 106.03 & 2.7311 & 0.982 \\
89 & Limestone & 2.14 & 0.014 & 282.12 & 2.9530 & 0.979 \\
103 & Limestone & 3.06 & 0.265 & 187.79 & 2.9261 & 0.998 \\
$108-2$ & Limestone & 2.14 & 0.287 & 216.12 & 2.8664 & 0.999 \\
$109 \mathrm{~A}$ & Limestone & 1.76 & 0.059 & 335.07 & 2.9051 & 0.999 \\
$114 \mathrm{~A}$ & Limestone & 2.25 & 0.632 & 145.23 & 2.8544 & 0.998 \\
$132-1$ & Limestone & 2.24 & 0.241 & 188.11 & 2.9413 & 0.995 \\
\hline
\end{tabular}

$\Phi$-porosity; $K$-permeability, $10^{-3} \mu \mathrm{m}^{2} ; \eta$-the ratio of pore radius to pore-throat radius; $D$-fractal dimension

$D$ is the fractal dimension, dimensionless number; $P_{\min }$ is the capillary pressure corresponding to the largest porethroat, MPa.

From formula (2), it can be seen that there is a linear relationship between the logarithm of the reservoir capillary pressure and the corresponding logarithm of the saturation of the wetting phase. Therefore, we can use the mercury-intrusion test results for linear regression analysis to obtain the pore fractal dimension $D$ that reflects the pore structure characteristics. According to the fractal theory, the fractal dimension in the three-dimensional Euclidean space is between 2 and 3 . The smaller the fractal dimension is, the more regular the pore shape, the smoother the pore surface, the better the reservoir pore permeability. However, the pore permeability of the reservoir is poor. A fractal dimension greater than 3 indicates that the corresponding pores do not have fractal features [41, 42].

For rocks with better porosity within the reservoir, there is a good linear relationship between the logarithm of capillary pressure and the logarithm of the saturation of the wetting phase (Equation 2). The pore structure has good statistical self-similarity. As the fractal dimension decreases, the pore structure becomes better. The fractal dimension of the sample is shown in Table 2. The fractal dimension of the five sandstone samples is 2.7066 to 2.8035 , with an average of 2.7523. The fractal dimension of the six limestone samples is 2.8544 to 2.9530 , with an average of 2.9077. Moreover, the fractal dimension of sandstone is smaller than that of limestone, so the pore structure of sandstone is more regular than limestone. Taking the two representative samples $\mathrm{H} 19$ (Figure 7a) and 58 (Figure 7b) in the target layer of the study area as examples, the porosity of the two samples was $6.13 \%$ and $3.96 \%$, respectively. The relationship between the logarithm of the capillary pressure and the logarithm of the saturation of the wetting phase is: 

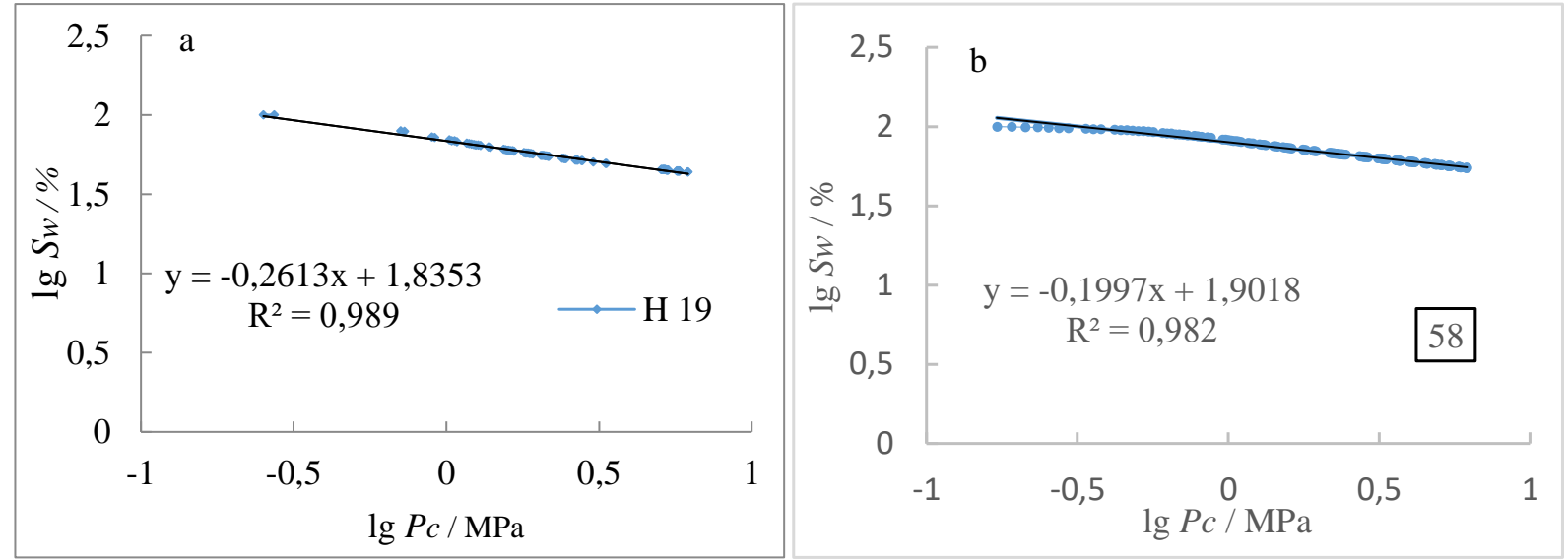

Figure 7: The relationship between capillary pressure and wetting phase saturation of $\mathrm{H} 19$ and 58 samples

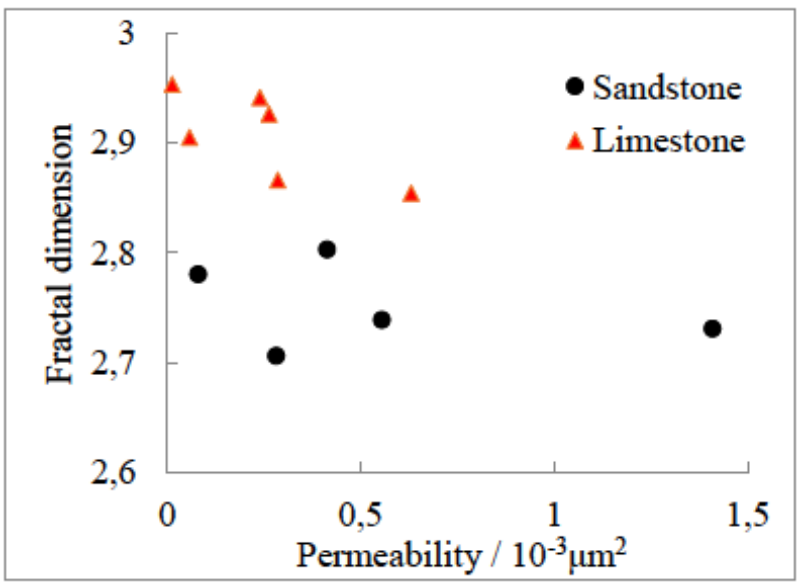

Figure 8: The relationship between fractal dimension and permeability

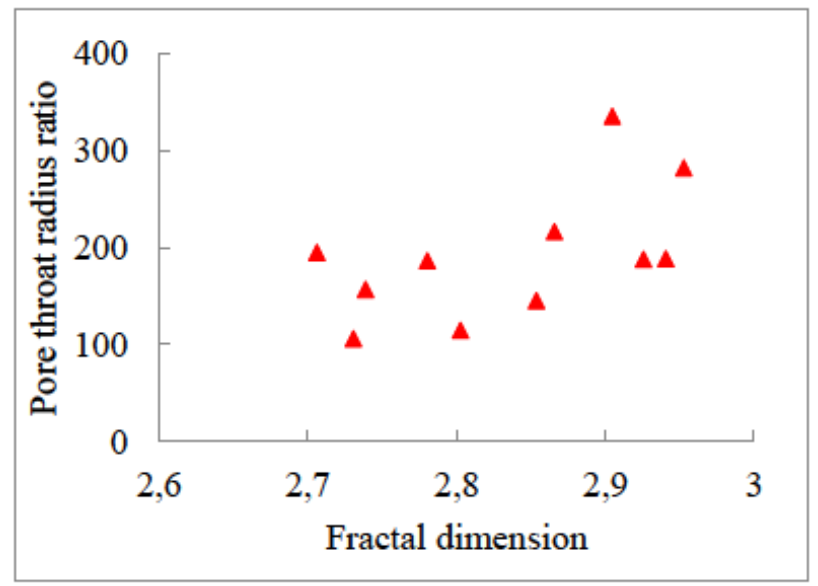

Figure 9: The relationship between fractal dimension and the porethroat radius ratio
H19 sample:

$$
\log S w=-0.261 \log P c+1.835 \quad R^{2}=0.989
$$

58 samples:

$$
\log S w=-0.199 \log P c+1.901 \quad R^{2}=0.982
$$

Using linear regression analysis, the fractal dimension of the pore structure of the two rock specimens is 2.7393 and 2.8035, respectively. Comparison shows that the fractal dimension of the H19 rock sample is smaller than the fractal dimension of the 58 rock sample. According to the foregoing rules, we can see that the pore structure of $\mathrm{H} 19$ is better, and the correlation between porosity and permeability is also better. The physical properties of the test of rock samples showed that the permeabilities of $\mathrm{H} 19$ and 58 samples were $0.556 \times 10^{-3} \mu \mathrm{m}^{2}$ and $0.415 \times 10^{-3} \mu \mathrm{m}^{2}$, respectively, confirming that the fractal dimension can reflect the quality of the rock pore structure. There is a good linear relationship between reservoir rock permeability and average throat radius (Figure 5), but the correlation between fractal dimension and rock reservoir permeability is not obvious (Figure 8). This is consistent with previous research [43]. It can be seen from Figure 9 that there is a certain correlation between the fractal dimension and the ratio of pore radius to pore-throat radius. As the fractal dimension increases, the ratio of pore radius to pore-throat radius increases.

\subsection{The ratio of pore radius to pore-throat radius distribution characteristics}

The reservoir's ratio of pore radius to pore-throat radius is one of the important parameters in the analysis of rock 


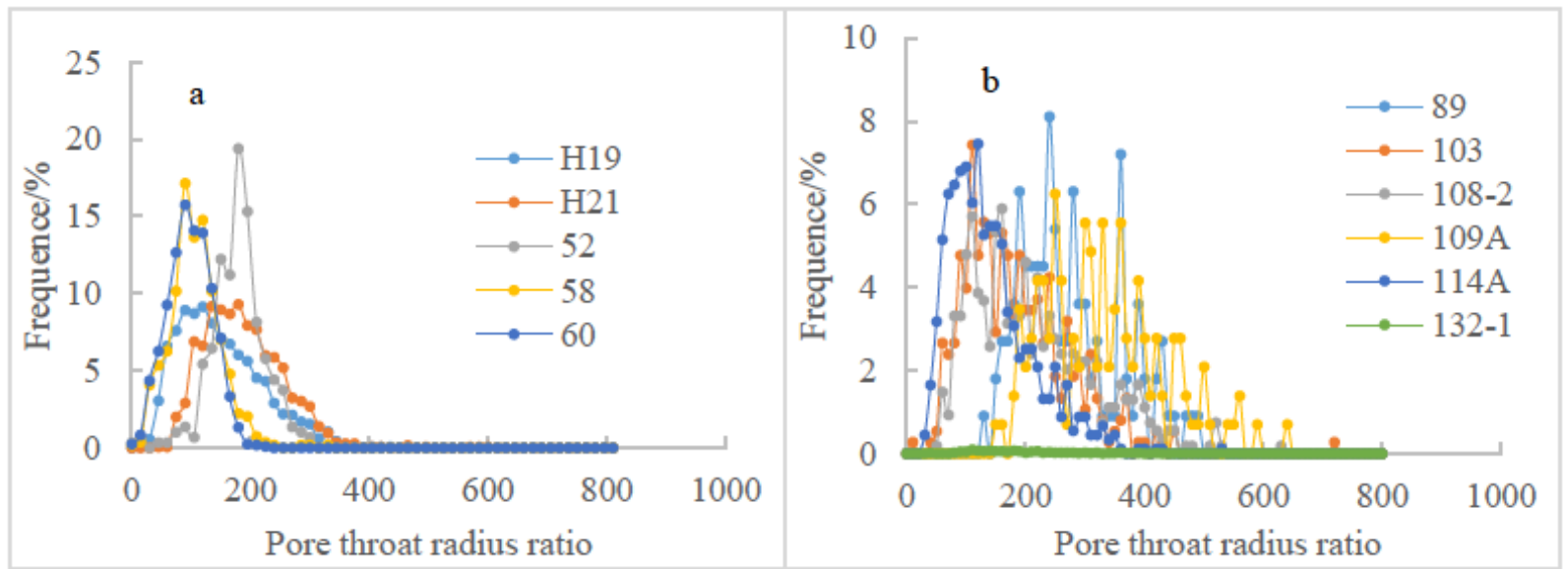

Figure 10: The ratio of pore radius to pore-throat radius size distribution by RMI of the samples

pore-throat characteristics. When the ratio between pore radius and throat radius is small, the throat's ability to restrain oil (gas) is small. The connection of large throats is conducive to the recovery of oil and gas in pores. On the contrary, when the throat radius is relatively large, it indicates that the pores are connected by the smaller throats, and oil and gas must overcome relatively large capillary forces when passing through the narrow throats. This is not conducive to the recovery of oil and gas in pores [ 44 , 45]. It can be seen from Figure 10 that the sandstone's ratio of pore radius to pore-throat radius (Figure 10a) is mainly distributed between 30 and 300, and the limestone's ratio of pore radius to pore-throat radius (Figure 10b) is mainly distributed between 40 and 480 . Therefore, compared to the conventional reservoir ratio of pore radius to porethroat radius, the ratio of pore radius to pore- throat radius of tight oil reservoirs is relatively large. Advanced technological transformation measures must be adopted to increase the radius of the throat and reduce the ratio of pore radius to pore-throat radius, so as to improve the development effect of the tight oil.

\section{Conclusions}

1. The oil reservoirs of the Sha-1 Section and Da'anzhai Section in the Shaxiamiao Formation of the LowerMiddle Jurassic in the Sichuan Basin are typical tight oil reservoirs. The permeability is $<0.1 \times 10^{-3} \mu \mathrm{m}^{2}$. The distribution characteristics of the pore radius of sandstone and limestone are similar, and the main distribution is between $100 \mu \mathrm{m}$ and $190 \mu \mathrm{m}$, the average pore radius is $160 \mu \mathrm{m}$.
2. The distribution of the throats of sandstone and limestone is quite different. The distribution of the throat of sandstone samples is relatively concentrated, and the distribution of the throat of limestone samples is relatively sparse. The throat radius of sandstone is generally between $0.2 \mu \mathrm{m}$ and $1.8 \mu \mathrm{m}$, and the average throat radius is about $0.5 \mu \mathrm{m}$. The throat radius of limestone is mainly between $0.1 \mu \mathrm{m}$ and $2.1 \mu \mathrm{m}$, and the average throat radius is about $0.7 \mu \mathrm{m}$. A good positive correlation exists between the average throat radius and permeability, indicating that the permeability is mainly controlled by the throat.

3. The pore structure of reservoir rocks has fractal features that can be characterized quantitatively by fractal dimensions. Studies show that the smaller the fractal dimension, the better the pore structure. The fractal dimension of sandstone is smaller than that of limestone, so the pore structure of sandstone is more regular than limestone. The correlation between the fractal dimension and the rock reservoir permeability is not obvious.

4. The ratio of pore-throat radii between sandstone in the first sand section and the Da'anzhai Section is relatively large, indicating that the pores are connected by the smaller throat, and oil and gas passing through the narrow throat need to overcome relatively large capillary forces, resulting in low oil displacement efficiency. For tight oil reservoirs, during the development process, emphasis was placed on increasing the radius of the throat and reducing the radius of the pores. Therefore, the pore-throat radius ratio can be reduced so that the development effect of tight oil can be improved. 
Acknowledgement: We gratefully acknowledge the financial support from the National Science and Technology Major Project (2017ZX05013-001).

\section{References}

[1] Zandong S., Unconventional oil and gas exploration and development, 2011, Beijing, Petrol. Industry Press.

[2] Caineng Z., Shizhen T., et al., Unconventional petroleum geology, 2011, Beijing, Geological Publishing House.

[3] Johnstone B., Bakklen black gold, Leader-Poster, 2007, 6.

[4] Chengzao J., Caiceng Z., Jianzhong L., et al., Evaluation criteria, main types, basic characteristics and resource prospects of tight oil in China, Acta Petrolei- Sinica, 2012, 33(3), 343-350.

[5] Caineng Z., Zhi Y., Rukai Z., et al., Unconventional oil and gas exploration, development and theoretical and technological advances in China, Geological J., 2015, 89(6), 979-1007.

[6] Behzad G., Allen G., Thomas E., et al., Saturation dependence of transport in porous media predicted by percolation and effective medium theories, Fractals, 2015, 23(1), 1540004.

[7] Huawei Z., Zhengfu N., Qing W. et al., Petrophysical characterization of tight oil reservoirs using pressure-controlled porosimetry combined with rate-controlled porosimetry, Fuel, 2015, 154, 233-242.

[8] Hao W., Chunlin Z., Youliang J. et al., An improved method of characterizing the pore structure in tight oil reservoirs: Integrated NMR and constant-rate-controlled porosimetry data, J. Petrol. Sci. Eng., 2018, DOI: 10.1016/j.petrol.2018.03.065.

[9] Qianhua X., Hao Z., Zhengming Y. et al., Low temperature nitrogen adsorption experiment in typical tight oil region in China, Special Oil and Gas Reservoirs, 2015, 22(4), 82-85.

[10] Bo L., Hongsong L., Yongjun W. et al., Micro-pore characteristics of tight oil reservoirs in the Da'anzhai Formation of the Ziliujing Formation in Central Sichuan Basin, J. Chengdu Univ. Techn. Sci. \& Technol. Ed., 2018, 45(2), 211-220.

[11] Shangwen Z., Huaqing X., Wei G., Experiments on the movable fluid of the Jurassic tight oil reservoir in the Middle Sichuan Basin, J. Liaoning Techn. Univ. (Natural Science Ed.), 2014(6), 768-772.

[12] Kelai X., Yingchang G., Beyene G. et al., How does the porethroat size control the reservoir quality and oiliness of tight sandstones? The case of the Lower Cretaceous Quantou Formation in the southern Songliao Basin, China, Marine Petrol. Geology, 2016, 76, 1-15.

[13] Zhengming Y., Experimental technique for special low-ultra-low permeability reservoirs, 2012, Beijing, Petrol. Industry Press.

[14] Shaoyong W., Jianzhong L., Denghua L. et al., The potential of tight oil resource in Jurassic Da'anzhai Formation of the Gongshanmiao oil field, central Sichuan Basin, Geology in China, 2013, 40(2), 477-486.

[15] Xizhe L., Zhenhua G., Yujin W. et al., Geological characteristics and development strategies for Cambrian Longwangmiao Formation gas reservoir in Anyue gas field, Sichuan Basin, SW China, Petrol. Explor. Development, 2017, 44(3), 398-406.

[16] Xizhe L., Zhenhua G.,Yong H. et al., Efficient development strategies for large ultra-deep structural gas fields in China, Petrol. Explor. Development, 2018, 45(1), 111-118.
[17] Bin Z., Jian H., Jiajing Y. et al., Control of tight source oil distribution by source rocks: A case study of Da'an Village in the Sichuan Basin, Bulletin of Mineralogy, Geochem., 2015, 34(1), 45-54.

[18] Wei L., Zhengming Y., Xizhe L. et al., A method to select representative rock samples for digital core modeling, Fractals, 2017, 25(4),1740013.

[19] Wei L., Xizhe L., Zhengming Y. et al., Construction of dual pore 3$D$ digital cores with a hybrid method combined with physical experiment method and numerical reconstruction method, Transport in porous media, 2017, 120(1), 227-238.

[20] Zhengming Y., Yingzhi Z., Mingqiang H. et al., Comprehensive reservoir evaluation method for low permeability oil fields, Acta PetroleiSinica, 2006, 27(2), 64-67.

[21] Dianshi X., Zhengyuan L., Shu J. et al., Comparison and integration of experimental methods to characterize the full-range pore features of tight gas sandstone-A case study in Songliao Basin of China, Journal of Natural Gas Science \& Engineering, 2016, 34,1412-1421.

[22] Hao W., Chunlin Z., Youliang J. et al., Size characterization of pore-throat in tight sandstone and control of reservoir properties: A case study of Yanchang Formation in Longdong area of Ordos Basin, Acta PetroleiSinica, 2017, 38(8), 876-887.

[23] Weicheng L., Yanmei Z., Fang W. et al., Micropore-throat characteristics of tight oil reservoirs using constant-pressure mercuryintrusion technique: A case study of the Upper Triassic Yanchang Formation in the Ordos Basin, Lithologic Reservoirs, 2012, 24(6), 60-65.

[24] Daopin L., Development of low permeability sandstone oilfield,1997, Beijing, Petrol. Industry Press.

[25] Qiang L., Study on the seepage mechanism of tight reservoirs in Sichuan Basin,2014, Beijing, Graduate University of Chinese Academy of Sciences (Institute of Fluid Dynamics).

[26] Ganesh C., et al., Integrated management of oilfield water injection development, 2001, Beijing, Petrol. Industry Press.

[27] Ruifei W., Pingping S., Ziqi S. et al., Microscopic pore-throat characteristics of reservoirs in ultra-low permeability sandstone reservoirs, Editorial office of ACTA Petrolei Sinica, 2009, 30(4), 560-563.

[28] Zhihai C., Microscopic pore-throat distribution and evaluation of movable oil in ultra-low permeability reservoirs: A case study of the Yingcheng Formation reservoir in Shiwu Oilfield, Petrol. Geology Sinica, 2011, 33(6), 657-661.

[29] Wei X., Qun L., Xiangui L. et al., Proposed pressure gradient for low permeability reservoirs, Petrol. Explor. Development, 2009, 36(2), 232-236.

[30] Yadong Q., Ailin J., Zhengming Y. et al., Feasibility evaluation method for water injection development in ultra-low permeability sandstone reservoirs, J. Centr. South Univ. Nat. Sci., 2014(11), 3886-3892.

[31] Gavin L., Pre-Dancy flow: A missing piece of the improved oil recovery puzzle,SPE/DOE Symposium on Improved Oil Recovery, Soc. Petrol. Eng., 2004.

[32] Yuan H., Swanson B., Resolving pore-space characteristics by rate-controlled porosimetry, Spe Formation Evaluation, 1989, 4(1), 17-24.

[33] Junchang S., Zhengming Y., Qianhua X., Development history of constant speed mercury injection technology and its application in oil and gas field development, Adv. Porous Flow, 2011, 1(1), 1-7. 
[34] Mandelbrot B., The fractal geometry of nature,1982, New York, WH Freeman \& Co.

[35] Xinfang M., Shicheng Z., Zhaoxin L., Fractal dimension of pore structure calculated by piecewise regression method, J. China Univ. Petrol., 2004, 28(6), 54-56.

[36] Xianguo Z., Tao Z., Chengyan L., Evaluation of pore structure of low permeability reservoir based on pore fractal feature, Lithologic Reservoirs, 2013, 25(6), 40-45.

[37] Naveen P., Asif M., Ojha K., Integrated fractal description of nanopore structure and its effect on $\mathrm{CH} 4$, adsorption on Jharia coals, India, Fuel, 2018, 232,190-204.

[38] Rui S., Mengmeng C., Jianjun L. et al., A pore-scale simulation on thermal-hydromechanical coupling mechanism of rock, Geofluids, 2017(21), 7510527.

[39] Rui S., Mengmeng C., Jianjun L., A correlation for heat transfer and flow friction characteristics of the offset strip fin heat exchanger, Int. J. Heat \& Mass Transf., 2017, 115(PB), 695-705.

[40] Rui S., Jianjun L., Mengmeng C., A new method to reconstruct structured mesh model from micro-computed tomography images of porous media and its application, Int. J. Heat \& Mass Transf., 2017, 109, 705-715.
[41] Liang Y., Ruicheng G., Qi'an M. et al., Sequence characteristics and control factors of the Lower Cretaceous in the Tanan Sag, Tamuztag Basin, China, Geological J., 2009, 83(6),827-835.

[42] Wei L., Xizhe L., Zhengming Y. et al., A new improved threshold segmentation method for scanning images of reservoir rocks considering pore fractal characteristics, Fractals, 2018, 26(2),1840003.

[43] Yu S., Yadong Q., Zhengming Y. et al., Fractal study of lowpermeability reservoirs based on constant rate mercury injection, Petrol. Geology Rec., 2009, 16(2), 88-90.

[44] Rui S., Mengmeng C., Jianjun L., Single and multiple objective optimization of a natural gas liquefaction process, Energy, 2017, 124, 19-28.

[45] Ruifei W., Pingping S., Ziqi S. et al., Micro pore-throat characteristics of ultra-low permeability sandstone reservoirs, Acta Petrolei Sinica, 2009, 30(4), 560-563. 